\title{
The Impact of Long-acting Paliperidone in Reducing Hospitalizations and Clinical Severity in Recent Onset Schizophrenia: A Mirror-image Study in Real-world Clinical Setting
}

\author{
Vjekoslav Peitl ${ }^{1,2, *}$, Branka Aukst Margetić ${ }^{1,2}$, Branka Vidrih ${ }^{1,2}$, Dalibor Karlović ${ }^{1,2, *}$ \\ ${ }^{1}$ Department of Psychiatry, University Hospital Center Sestre Milosrdnice, ${ }^{2}$ Catholic University of Croatia, Zagreb, Croatia
}

\begin{abstract}
Objective: Schizophrenia is a debilitating disease that disrupts the lives of many affected individuals and exerts a toll on the health system. Only few studies assessed once-monthly injectable formulation of paliperidone palmitate (PP-1M) and other long-acting antipsychotics in recent onset schizophrenia (ROS). To evaluate whether PP-1M is efficacious in reducing frequency and length of hospitalizations and psychosis symptom severity in patients with ROS.

Methods: This mirror-image study included 112 patients, suffering from ROS admitted in a psychiatric ward and successively treated with PP-1M for 1-year. Other psychotic disorders were excluded. We collected socio-demographic data of all subjects included, number and days of hospitalization, as well as Clinical Global Impression-Severity scale (CGI-S) and Clinician-Rated Dimensions of Psychosis Symptom Severity (CRDPSS) scores at the initiation and after 1-year of PP treatment.

Results: After 1-year PP-1M treatment, mean scores of both CGI and CRDPSS significantly decreased $(p<0.001)$, as well as the mean number of hospitalizations $(p=0.002)$ and total hospitalization days $(p<0.001)$ in comparison with those of the previous year.

Conclusion: Our results suggest that PP-1M can be considered as an important therapeutic option in patients with ROS. Its use led to a meaningful reduction in the patient's use of hospital services, as well as a significant clinical improvement of psychotic symptoms in our sample.
\end{abstract}

KEY WORDS: Antipsychotic agents; Paliperidone palmitate; Pragmatic clinical trials; Psychotic disorders.

\section{INTRODUCTION}

Schizophrenia, with its chronic and often debilitating course exerts a heavy toll on the society as a whole, but especially health-care and social services [1]. Significant portion of schizophrenia related costs are those associated with prescribing antipsychotic medication [2]. However, poor adherence to psychiatric treatment, or lack of it, has previously been associated with increased rates of illness relapse and hospital utilization, unfavourable prognosis, decreased quality of life, social functioning

Received: December 3, 2020 / Revised: January 20, 2021

Accepted: January 23, 2021

Address for correspondence: Dalibor Karlović

Department of Psychiatry, University Hospital Centre Sestre

Milosrdnice, Vinogradska cesta 29, 10000 Zagreb, Croatia

E-mail: dalibor.karlovic@gmail.com

ORCID: https://orcid.org/0000-0001-6538-7240

*These authors contributed equally to this study. and productivity [3]. On the other hand, regular use of antipsychotics is patients with schizophrenia is associated with reduced mortality relative to those patients that do not take prescribed medication [4]. Bearing that in mind, first years after schizophrenia onset represent a critical period for interventions to prevent progressive brain changes, worse clinical outcomes, higher rate of relapse and chronic patterns of disability [4-7]. Improving treatment adherence, while reducing the risk of relapse, has therefore become one of the major focuses of psychiatric interventions and research. Although there were other approaches to tackle the issue of treatment non-adherence, long acting injectable antipsychotics (LAI) are slowly becoming the most utilized one. Even though the majority of studies and meta-analyses reported LAI superiority over oral antipsychotics in preventing hospitalizations and reducing bed stays [8-10], there have also been reports of non-significant differences [11].

(c) This is an Open-Access article distributed under the terms of the Creative Commons Attribution Non-Commercial License (http://creativecommons.org/licenses/by-nc/4.0) which permits unrestricted non-commercial use, distribution, and reproduction in any medium, provided the original work is properly cited. 
Given that the main target is to resolve psychosis, prevent its return and improve functioning in the short and long-term, one of the viable therapeutic options is to utilize LAl's (especially second-generation antipsychotics) in recent-onset schizophrenia [10]. It is a relatively new idea to manage schizophrenia with LAl's right from the moment of first diagnosis [12]. In general, LAI therapy was not, until relatively recently, considered as a first-line option for first episode (FES) and recent onset schizophrenia (ROS), but was dominantly used in frequently relapsing and non-adherent patients. However, there is an evident change in therapeutic trends for recent-onset schizophrenia, with the increasing number of associations proposing the use of LAl's as first line treatment in schizophrenia spectrum disorders [10].

Paliperidone palmitate (PP-1M) is a once monthly LAI formulation of the paliperidone palmitoyl ester that became commercially available in the early 2010's. PP-1M has proven effective in a number of studies (especially observational ones) in reducing hospitalizations, number of bed days and treatment related costs in patients with schizophrenia [2,13-17]. Contrary to that, randomized controlled trials have generally shown comparable efficacy of LAI and oral formulations in preventing relapse, symptom reduction and treatment discontinuation in schizophrenia [11]. Although available, there are very few studies that primarily focused on FES and/or ROS and solely on PP-1M. Study by Medrano and associates included PP-1M, among seven other LAl's, and reported symptomatic and functional improvement in FES, however to a lesser extent than oral antipsychotics [18]. Those results are in contrast with improvement reported by other authors and meta-analyses $[19,20]$. Furthermore, in one identified study focusing specifically on PP-1M in recent diagnosed schizophrenia authors reported significantly lower rates of relapse, as well as clinical and functional improvement [21]. Studies with mirror-type designs that compared between specular periods of oral and LAI antipsychotics in the same patient or retrospective studies collecting data from national or international registers or COhort studies conducted in clinical settings confirmed LAI antipsychotic efficacy in improving schizophrenia's clinical course [16,22-24].

In the current study we evaluated whether PP-1M has an effect on hospitalization rates, number of bed days, clinical improvement and reduction of psychosis symp- tom severity in patients with ROS. We hypothesized that patients would benefit from introduction of PP-1M, resulting in lower rate of hospitalizations and bed days.

\section{METHODS}

\section{Participants}

Study was performed on 112 patients suffering from ROS (patients diagnosed with schizophrenia according to the Diagnostic and Statistical Manual of Mental Disorders [DSM] criteria made 1-2 years previously and at least one psychiatric hospitalization in the preceding 12 months; this may have included the current acute episode), whose sociodemographic and clinical parameters are presented in Table 1. The inclusion criteria for this study was the diagnosis of schizophrenia, using the DSM-5 criteria, while other psychotic disorders (e.g., psychotic disorder due to another medical condition and substance/medication induced psychotic disorders) were excluded. For this study, a trained psychiatrist using a structured clinical interview for DSM-5 disorders (SCID-5) made the diagnosis of schizophrenia [25]. As this was a naturalistic study, we included patients with organic comorbidity (e.g., arterial hypertension, diabetes, chronic obstructive pulmonary disease, allergies), which were present in $22.3 \%$ of patients. However, that organic comorbidity was ruled out as a possible cause of psychosis. Patients were included if they had received two loading doses of PP-1M and had a prescription for an oral antipsychotic 1 year before initiating PP-1M. Patients were not eligible if they were considered by the investigator to be treatment-resistant or unsuitable for treatment with an atypical oral antipsychotic or had received clozapine within the previous 6 months. Other exclusion criteria included pregnancy, as well as history or current presence of extrapyramidal symptoms and/or hyperprolactinaemia, or a history of neuroleptic malignant syndrome. In the final analysis, we did not include 23 patients who did not complete one-year PP-1M treatment (12 monthly applications) due to development of marked extrapyramidal symptoms or hyperprolactinemia that warranted medication change, or were lost to follow up or had incomplete study data. Upon applying exclusion criteria, out of 163 patients considered for this study, 112 met the criteria and were included in the analysis (Fig. 1).

Prior to introduction of PP-1M, majority of patients had been treated with oral risperidone [26] or aripiprazole 
Table 1. Sociodemographic and clinical characteristics of patients with recent onset schizophrenia

\begin{tabular}{|c|c|c|c|c|c|}
\hline \multirow{2}{*}{ Variable } & \multirow{2}{*}{ Value } & \multicolumn{2}{|c|}{$95 \%$ Confidence interval } & \multirow{2}{*}{$\mathrm{F}$ value } & \multirow{2}{*}{$p$ value } \\
\hline & & Lower bound & Upper bound & & \\
\hline Age $(y r)$ & $31.6 \pm 5.5$ & & & & \\
\hline Duration of illness (yr) & $1.6 \pm 0.3$ & & & & \\
\hline \multicolumn{6}{|l|}{ Sex } \\
\hline Male & $76(67.9)$ & & & & \\
\hline Female & $36(32.1)$ & & & & \\
\hline \multicolumn{6}{|l|}{ Work status } \\
\hline Employed & $44(39.3)$ & & & & \\
\hline Unemployed & $51(45.5)$ & & & & \\
\hline Retired & $15(13.4)$ & & & & \\
\hline Student & $2(1.8)$ & & & & \\
\hline \multicolumn{6}{|l|}{ Education level } \\
\hline Elementary school & $7(6.3)$ & & & & \\
\hline High school & $86(76.8)$ & & & & \\
\hline University & $19(16.9)$ & & & & \\
\hline \multicolumn{6}{|l|}{ Marital status } \\
\hline Married & $20(17.9)$ & & & & \\
\hline Unmarried & $84(75.0)$ & & & & \\
\hline Divorced & $8(7.1)$ & & & & \\
\hline \multicolumn{6}{|l|}{ Place of residence } \\
\hline Urban & $108(96.4)$ & & & & \\
\hline Rural & $4(3.6)$ & & & & \\
\hline \multicolumn{6}{|l|}{ Living with the family } \\
\hline Primary & $66(58.9)$ & & & & \\
\hline Secondary & $19(17.0)$ & & & & \\
\hline Alone & $19(17.0)$ & & & & \\
\hline Other & $8(7.1)$ & & & & \\
\hline \multicolumn{6}{|l|}{ Psychiatric heredity } \\
\hline Positive & $34(30.4)$ & & & & \\
\hline Negative & $78(69.6)$ & & & & \\
\hline \multicolumn{6}{|l|}{ Substance abuse } \\
\hline Positive & $36(32.1)$ & & & & \\
\hline Negative & $76(67.9)$ & & & & \\
\hline \multicolumn{6}{|l|}{ Specific type of substance abused } \\
\hline Cannabis & $20(17.9)$ & & & & \\
\hline Heroin and opiates & $3(2.7)$ & & & & \\
\hline Multiple substances & $13(11.5)$ & & & & \\
\hline Negative & $76(67.9)$ & & & & \\
\hline \multicolumn{6}{|l|}{ Organic comorbidity } \\
\hline Positive & $25(22.3)$ & & & & \\
\hline Negative & $87(77.7)$ & & & & \\
\hline Hospitalization days before PP & $13.6 \pm 5.8$ & 12.5 & 14.8 & 43.065 & $<0.001$ \\
\hline Hospitalization days after PP & $7.0 \pm 6.4$ & 5.7 & 8.3 & & \\
\hline Number of hospitalizations before PP & $1.1 \pm 2.3$ & 0.6 & 1.5 & 10.569 & 0.002 \\
\hline Number of hospitalizations after PP & $0.3 \pm 0.6$ & 0.2 & 0.4 & & \\
\hline CGI before PP & $5.2 \pm 0.8$ & 5.0 & 5.4 & 831.853 & $<0.001$ \\
\hline CGl after PP & $2.6 \pm 0.5$ & 2.4 & 2.7 & & \\
\hline CRDPSS before PP & $14.8 \pm 4.3$ & 13.9 & 15.7 & 518.422 & $<0.001$ \\
\hline CRDPSS after PP & $8.6 \pm 3.8$ & 7.8 & 9.3 & & \\
\hline
\end{tabular}

Values are presented as mean \pm standard deviation or number $(\%)$.

$\mathrm{PP}$, paliperidone palmitate once monthly long acting injectable antipsychotic; CGI, clinical global impression scale; CRDPSS, clinician-rated dimensions of psychosis symptom severity. 


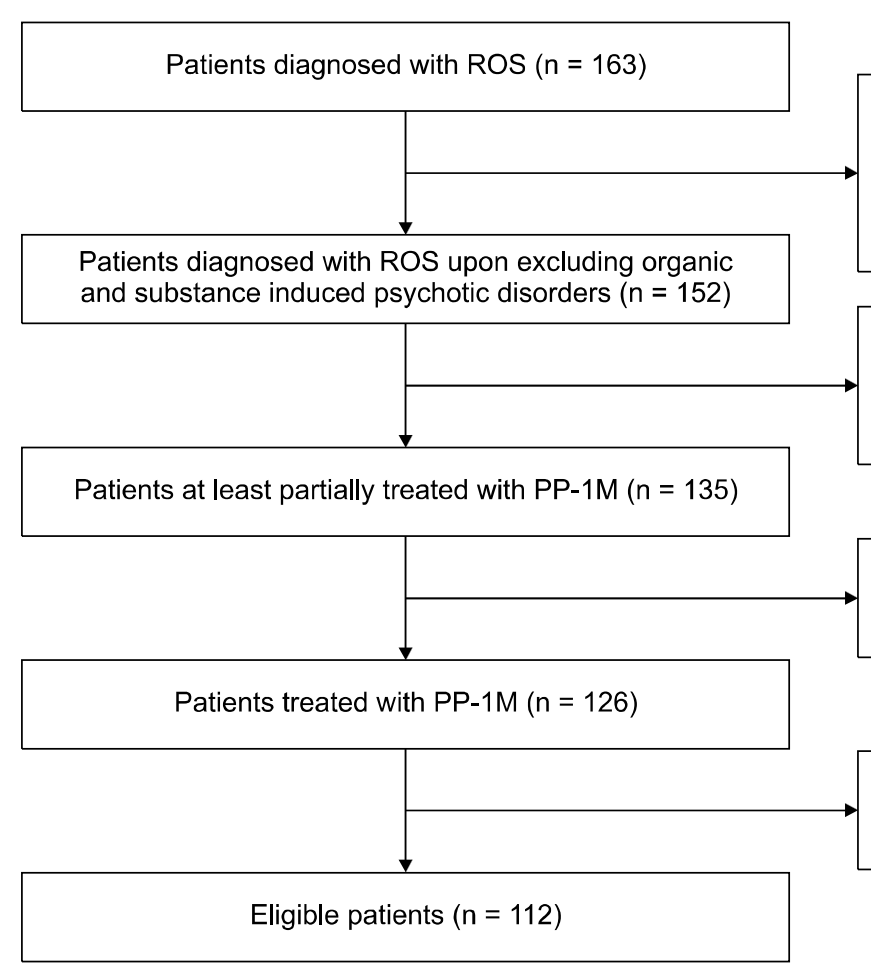

[27], 12 patients with amisulpride, 10 with haloperidol, 8 with olanzapine, 7 with fluphenazine, 6 with ziprasidone and 5 with quetiapine. Five of the patients included were previously treated with a combination of risperidone and aripiprazole. There were no patients treated with oral paliperidone, as it is unavailable in Croatia. In 37 patients previously treated with oral risperidone, we decided to reintroduce the same medication, with subsequent switch to the PP-1M, as the cause of relapse was poor adherence to treatment recommendations, especially daily regimen of risperidone intake.

The recommended starting dose for oral risperidone was 4 to $6 \mathrm{mg} /$ day, depending on the patient's symptoms and investigator's opinion. The investigators were permitted to titrate the dose up to $8 \mathrm{mg} /$ day based on clinical judgement. Mean daily dose of oral risperidone for the whole sample was $5.7 \mathrm{mg} /$ day. Upon introduction of PP-1M, patients were treated with a $150 \mathrm{mg}$ intramuscular injection, followed by a 100 mg intramuscular injection after one week. Oral risperidone was continued until the second loading dose of PP-1M. During that one-week period, patients received $4 \mathrm{mg} /$ day oral risperidone unless they were currently receiving doses above $8 \mathrm{mg} /$ day, in which case they received oral risperidone $6 \mathrm{mg} /$ day. A dose reduction of PP-1M lower than $100 \mathrm{mg}$ monthly was
Patients with psychotic episode due to organic psychotic disorder or substance induced psychotic disorder $(n=11)$

Patients not prescribed PP-1M due to physiological and medical concerns $(n=17)$

Patients that discontinued

PP-1M due to adverse effects $(n=9)$

Patients with incomplete study data or lost to follow up $(n=14)$
Fig. 1. Data set for study analysis. ROS, recent onset schizophrenia; PP-1M, paliperidone palmitate once monthly long acting injectable.

permitted if patients experienced tolerability issues, which was the case in 13 patients. In that case, we reduced the PP-1M dose to $75 \mathrm{mg}$ monthly and continued that dose for the remainder of the study or until medication change (for 9 patients that discontinued PP-1M due to adverse effects). Informed consent was obtained from all included patients after a complete and extensive description of the study profile. Treatment with PP-1M was not compulsory, nor was participation in this study. The study was approved by Ethics Committee of the University Hospital Centre Sestre milosrdnice (no. EP-6820/13-18).

\section{Medical Examination and Data Collection}

This mirror-image study included patients that had been admitted for inpatient treatment at the University Hospital Centre Sestre milosrdnice in the period from May 2017 to February 2019. One-year follow up was successfully completed at the end of March 2020. We collected data on the number of psychiatric hospitalizations and the number of bed days for 1 year before and 1 year after initiating PP-1M. Clinical Global Impression-Severity scale (CGI-S) [28] and Clinician-Rated Dimensions of Psychosis Symptom Severity (CRDPSS) [27] scores were obtained at the initiation of PP-1M and at the end of a one year follow up period. We chose to assess the CGI and CRDPSS 
scores for several reasons. First, we recognize the heterogeneity and complexity of schizophrenia, and a need to encompass all aspects of the disease. On the other hand, we also recognise the need for the reduction of workload while using diagnostic and prognostic scales in routine clinical practise. In order to reconcile these two contradicting needs we chose these two scales. The CGI is one of the most commonly used brief rating scales in mental health trials making it an excellent tool in every day work. The brevity and simplicity of the tool make it more convenient to use routinely instead of more robust tools such as Positive and Negative Syndrome Scale (PANSS), and several studies have demonstrated the validity of the CGI by linkage to these scales [29-31]. Additionally, in order to better understand the clear heterogeneity in symptoms during ROS we needed a tool made for multidimensional assessment. CRDPSS is such a tool, being an 8-item scale for assessment of psychotic symptom severity. This scale is designed to better capture significant variations in the severity of symptoms and may be used in research on pathophysiological mechanisms [27]. Other parameters, including age, sex, education level, marital status, place of residence, psychiatric heredity, substance abuse, organic comorbidity, illness duration, were obtained at initiation of PP-1M

\section{Statistical Analyses}

Sociodemographic and clinical characteristics of patients are presented by frequencies and percent or by means and standard deviation (SD), depending on the variable (nominal or continuous). Normal distribution was assessed for all measures using the Kolmogorov - Smirnov test. In order to determine if there are statistically significant differences between number of hospitalizations, days of hospitalization, CGI and CRDPSS scores, one year before and one year after initiation of PP, we created a one-way repeated-measures ANOVA statistical model. As we had four different comparations in the same model, we used Bonferroni correction in order to rule out type I errors (Bonferroni corrected $p$ value $=0.05 / 4=0.012$ ). We considered the difference to be statistically significant if the $p$ value was lower than 0.012 (i.e., 1.25\%). Statistics was performed with SPSS software (SPSS for Windows 20.0; IBM Co., Armonk, NY, USA).

\section{RESULTS}

Data were collected for 163 patients diagnosed with ROS. After applying the exclusion criteria, 112 patients remained for analysis (Fig. 1). Multivariate tests were used to test the influence of treatment with PP-1M on number of hospitalizations and hospitalization days, as well as on clinical characteristics of included patients. Multivariate model revealed statistical significance $(\mathrm{F}=233.229, p<$ 0.001).

Patients' sociodemographic and clinical details are given in Table 1. The mean age of the participants was $31.6 \pm$ 5.5 years. Among them, 76 (67.9\%) were male, and 36 $(32.1 \%)$ were female. Most patients $(76.8 \%)$ were high school graduates and either unemployed (45.5\%) or employed (39.3\%). Majority were unmarried $(75 \%)$ and living with their primary family (58.9\%). Regarding the hereditary loading, $69.6 \%$ were negative for psychiatric illness in their families. Substance abuse was present in $32.1 \%$ of included patients, with $17.9 \%$ abusing cannabis, $2.7 \%$ opiates and $11.5 \%$ multiple substances of abuse.

The mean duration of illness was $1.6 \pm 0.3$ years. Mean scores of clinical parameters, evaluated by CGI and CRDPSS, significantly decreased after initiating PP-1M. CGI score was reduced from $5.2 \pm 0.8$ to $2.6 \pm 0.5(F=831.853$ and $p<0.001$ ), while the CRDPSS score was reduced from $14.8 \pm 4.3$ to $8.6 \pm 3.8(\mathrm{~F}=518.422$ and $p<0.001)$.

\section{Number of Hospitalizations and Hospitalization Days}

The average number of hospitalizations in the year before starting PP- $1 \mathrm{M}$ was $1.1, \mathrm{SD}=2.3$; this decreased significantly, to $0.3, \mathrm{SD}=0.6$, the next year $(p=0.002)$. The mean total number of hospitalization days in the year before starting PP-1M was 13.6, SD $=5.8$, but this too decreased significantly, to 7.0, $\mathrm{SD}=6.4$, the year after $(p<$ 0.001).

\section{DISCUSSION}

In this naturalistic mirror image study of ROS patients, we established that after one year of treatment with PP-1M, the number of hospitalizations and the total number of bed days decreased significantly. Mean number of bed days decreased by almost 7 days, suggesting that PP-1M may have superior efficacy compared to that of or- 
al antipsychotics. Although similar results with PP-1M have been reported on several occasions in patients with schizophrenia, there is only a small number of available studies that focused on first episode and early schizophrenia. Two studies on patients with first episode schizophrenia, although not on PP-1M homogenous samples, also reported PP-1M outperforming oral antipsychotics $[19,20]$, as well as a study on a PP-1M homogenous sample in recent diagnosed schizophrenia (up to five years after first diagnosis) [21]. On the other hand, reported results are in contrast to some of the earlier reports in which LAI's (not only PP-1M) did not outperform oral antipsychotics in treating patients with first episode psychosis [18].

Beside reduction of hospitalizations and bed days, we established significant reductions of CGI and CRDPSS scores, reflecting a positive therapeutic effect of one-year treatment with PP-1M. Although other studies did not utilize CRDPSS in a population such as this, our findings of significant improvement on used scales are in line with the results of most studies that have shown significant alleviation of symptoms or improvement of functioning measured by scales such as CGI, PANSS, personal and social performance scale-PSP or global assessment of functioning-GAF [16,31-33].

Previous research reported that poor treatment adherence is the main reason that motivates prescription of $\mathrm{LAI}$ in first episode or later in psychotic disorder evolution $[8,9,18]$. It comes as no surprise, as one of the most powerful strengths of LAl's is their ability to enhance medication adherence as every application can be clearly documented. In terms of our sample, 14 patients were excluded due to incomplete study data or loss to follow-up, reflecting the issue of poor treatment adherence. This issue is especially interesting regarding the research setting, as observational studies tend to report superiority of LAI's over oral antipsychotics [8,9], while randomised control trials often do not [11]. It was argued that rigorous inclusion and follow-up criteria might bias the representation of the psychiatric population initiated on LAI antipsychotics $[9,14]$. Therefore, in a real-world sample, mirror studies might adequately represent the patients treated at everyday clinical setting, which we believe was the case in our sample.

Sociodemographic characteristics of patients in this study were well consistent with earlier population-based studies [33-35]. As expected for ROS, patients were mostly younger with median age at time of inclusion of 31.6 years. In our sample two thirds of included patients were male. Although gender differences in prevalence and incidence of schizophrenia in general population is a subject of debate [36], higher percentage of males in our sample reflects participants that were available for analysis upon applying inclusion and exclusion criteria outlined in Figure 1. Even though one of our exclusion criteria was substance-induced psychosis and none of the patients included in analysis had used substances immediately prior to their hospitalization, occasional substance use was relatively common in our sample of patients. Cannabis was found to be the most used substance, either alone (20\% of patients) or in combination with other psychoactive drugs of abuse (13\% of patients). This is in line with the prevalence of cannabis use in patients with schizophrenia, which is between $12 \%$ and $42 \%[37,38]$. Significantly higher than the prevalence in general population, which is approximately $3 \%$ to $5 \%$ [39]. While abuse of any psychoactive drugs can induce a transient psychosis, cannabis use has been increasingly identified as a possible trigger of long-lasting psychosis of the schizophrenia spectrum, especially in vulnerable people [40]. Cannabinoids augment the risk of progressing to schizophrenia up to two to four-fold [41].

This study has several limitations, some of them inherent to mirror image studies. Foremost, the study was designed as an observational mirror-image study in which each patient acts as its own control, therefore we cannot compare the efficacy of PP-1M to other antipsychotics. However, compared to randomised control trials, mirror image studies tend to recruit patients found and treated in everyday clinical practice. Secondly, all patients were recruited from a single centre in Croatia, possibly leading to a geographical bias. Thirdly, due to the nature of observational study there was no randomization. To mitigate the selection bias, we included all patients who were prescribed at least two doses of PP-1M initiation regimen. In the end, 1-year follow-up period may be too short to evaluate the long-term effect of PP-1M and long-term adherence to therapy.

Although previously there have been studies assessing $\mathrm{PP}-1 \mathrm{M}$ in first episode and recent diagnosed schizophrenia, this was the first study on a PP-1M homogenous sample that included patients within two years after diag- 
nosis of schizophrenia. In Croatia no such study, as well as no mirror-image study, has ever been done. Our results suggest that PP-1M can be considered as an important therapeutic option in patients with ROS. Its use led to a meaningful reduction in the patient's use of hospital services, as well as a significant clinical improvement of psychotic symptoms in our sample. However, further studies evaluating the long-term effects of LAI in this population are needed.

\section{Funding}

None.

\section{- Conflicts of Interest}

No potential conflict of interest relevant to this article was reported.

\section{Author Contributions}

Vjekoslav Peitl: Methodology, Writing - Reviewing and Editing, Supervision. Branka Aukst Margetić: Resources, Data Curation, Editing. Branka Vidrih: Investigation, Conceptualization, Writing-Original draft preparation. Dalibor Karlović: Conceptualization, Methodology, Formal analysis, Data curation, Supervision.

\section{口 ORCID}

Vjekoslav Peitl https://orcid.org/0000-0003-4163-6411 Branka Aukst Margetić

https://orcid.org/0000-0002-7830-224X

Branka Vidrih https://orcid.org/0000-0002-5366-560X

Dalibor Karlović ｈttps://orcid.org/0000-0001-6538-7240

\section{REFERENCES}

1. Karlović D, Peitl V, Silić A. Shizofrenije. Jastrebarsko:Naklada Slap;2019. Croatian.

2. Mahlich J, Olbrich K, Wilk A, Wimmer A, Wolff-Menzler C. Hospitalization rates and therapy costs of German schizophrenia patients who are initiated on long-acting injectable medication: a mirror-image study. Clin Drug Investig 2020; 40:355-375.

3. Ascher-Svanum H, Faries DE, Zhu B, Ernst FR, Swartz MS, Swanson JW. Medication adherence and long-term functional outcomes in the treatment of schizophrenia in usual care. J Clin Psychiatry 2006;67:453-460.

4. Torniainen M, Mittendorfer-Rutz E, Tanskanen A, Björkenstam C, Suvisaari J, Alexanderson K, et al. Antipsychotic treatment and mortality in schizophrenia. Schizophr Bull 2015;41:
656-663.

5. Robinson D, Woerner MG, Alvir JM, Bilder R, Goldman R, Geisler $\mathrm{S}$, et al. Predictors of relapse following response from a first episode of schizophrenia or schizoaffective disorder. Arch Gen Psychiatry 1999;56:241-247.

6. Zipursky RB, Menezes NM, Streiner DL. Risk of symptom recurrence with medication discontinuation in first-episode psychosis: a systematic review. Schizophr Res 2014;152:408 414.

7. Karson C, Duffy RA, Eramo A, Nylander AG, Offord SJ. Long-term outcomes of antipsychotic treatment in patients with first-episode schizophrenia: a systematic review. Neuropsychiatr Dis Treat 2016;12:57-67.

8. Kishimoto T, Nitta M, Borenstein M, Kane JM, Correll CU. Long-acting injectable versus oral antipsychotics in schizophrenia: a systematic review and meta-analysis of mirror-image studies. J Clin Psychiatry 2013;74:957-965.

9. Kishimoto T, Hagi K, Nitta M, Leucht S, Olfson M, Kane JM, et al. Effectiveness of long-acting injectable vs oral antipsychotics in patients with schizophrenia: a meta-analysis of prospective and retrospective cohort studies. Schizophr Bull 2018;44: 603-619.

10. Salgueiro M, Segarra R. Long-acting injectable second-generation antipsychotics in first-episode psychosis: a narrative review. Int Clin Psychopharmacol 2019;34:51-56.

11. Kishimoto T, Robenzadeh A, Leucht C, Leucht S, Watanabe K, Mimura M, et al. Long-acting injectable vs oral antipsychotics for relapse prevention in schizophrenia: a meta-analysis of randomized trials. Schizophr Bull 2014;40:192-213.

12. Horvitz-Lennon M, Predmore Z, Orr P, Hanson M, Hillestad $\mathrm{R}$, Durkin M, et al. Simulated long-term outcomes of early use of long-acting injectable antipsychotics in early schizophrenia. Early Interv Psychiatry 2019;13:1357-1365.

13. Mesones-Peral JE, Gurillo-Muñoz P, Sánchez-Sicilia MP, Miller A, Griñant-Fernández A. Hospitalizations and economic analysis in psychotic patients with paliperidone palmitate long-acting injection. Rev Psiquiatr Salud Ment 2017;10:33-37.

14. Vincent PD, Demers MF, Doyon-Kemp V, Duchesneau J, Halme A, Masson V. One year mirror-image study using paliperidone palmitate for relapse prevention of schizophrenia in four university hospitals in Canada. Schizophr Res 2017; 185:96-100.

15. Nielsen RE, Hessellund KB, Valentin JB, Licht RW. Secondgeneration $\mathrm{LA}$ / are associated to favorable outcome in a cohort of incident patients diagnosed with schizophrenia. Schizophr Res 2018;202:234-240.

16. Di Lorenzo R, Ferri P, Cameli M, Rovesti S, Piemonte C. Effectiveness of 1-year treatment with long-acting formulation of aripiprazole, haloperidol, or paliperidone in patients with schizophrenia: retrospective study in a real-world clinical setting. Neuropsychiatr Dis Treat 2019;15:183-198.

17. Oh SY, Jon DI, Hong HJ, Hong N, Yi JS, Roh D, et al. The impact of paliperidone palmitate on hospitalization in patients 
with schizophrenia: a retrospective mirror-image study. Clin Psychopharmacol Neurosci 2019;17:531-536.

18. Medrano S, Abdel-Baki A, Stip E, Potvin S. Three-year naturalistic study on early use of long-acting injectable antipsychotics in first episode psychosis. Psychopharmacol Bull 2018;48:25-61.

19. Privat AT, Baquero DB, Santacana AM, Sola VP. Decreased incidence of readmissions in first episode psychosis in treatment with long - acting injectable antipsychotics. Curr Psychopharmacol 2015;4:52-57.

20. Kishi T, Oya K, Iwata N. Long-acting injectable antipsychotics for the prevention of relapse in patients with recent-onset psychotic disorders: a systematic review and meta-analysis of randomized controlled trials. Psychiatry Res 2016;246:750755.

21. Schreiner A, Aadamsoo K, Altamura AC, Franco M, Gorwood $\mathrm{P}$, Neznanov NG, et al. Paliperidone palmitate versus oral antipsychotics in recently diagnosed schizophrenia. Schizophr Res 2015;169:393-399.

22. Tiihonen J, Haukka J, Taylor M, Haddad PM, Patel MX, Korhonen P. A nationwide cohort study of oral and depot antipsychotics after first hospitalization for schizophrenia. Am J Psychiatry 2011;168:603-609.

23. Fagiolini A, Rocca P, De Giorgi S, Spina E, Amodeo G, Amore M. Clinical trial methodology to assess the efficacy/effectiveness of long-acting antipsychotics: randomized controlled trials vs naturalistic studies. Psychiatry Res 2017;247:257-264.

24. Di Lorenzo R, Cameli M, Bolondi M, Landi G, Moretti V, Piemonte $\mathrm{C}$, et al. Paliperidone palmitate treatment in outpatient care setting: a naturalistic study. Psychopharmacol Bull 2016;46:36-53.

25. First MB, Williams JBW, Karg RS, Spitzer RL. Structured clinical interview for DSM-5 research version SCID-5-RV. Washington, D.C.:American Psychiatric Association Publishing;2015.

26. Savitz AJ, Xu H, Gopal S, Nuamah I, Ravenstijn P, Hough D, et al. Efficacy and safety of paliperidone palmitate 3-month versus 1-month formulation in patients with schizophrenia: comparison between European and non-European population. Neuropsychiatr Dis Treat 2019;15:587-602.

27. Barch DM, Bustillo J, Gaebel W, Gur R, Heckers S, Malaspina $\mathrm{D}$, et al. Logic and justification for dimensional assessment of symptoms and related clinical phenomena in psychosis: relevance to DSM-5. Schizophr Res 2013;150:15-20.

28. Guy W. ECDEU assessment manual for psychopharmacology. Rockville: United States Department of Health and Human Services; 1976.
29. Leucht S, Kane JM, Etschel E, Kissling W, Hamann J, Engel RR. Linking the PANSS, BPRS, and CGI: clinical implications. Neuropsychopharmacology 2006;31:2318-2325.

30. Rabinowitz J, Mehnert A, Eerdekens M. To what extent do the PANSS and CGI-S overlap? J Clin PSychopharmacol 2006;26: 303-307.

31. Rabinowitz J, Levine S, Martinez G. Concordance between measures of functioning, symptoms, and change: examining the GAF, CGI-S, CGI-C, and PANSS. J Clin PSychopharmacol 2010;30:478-480.

32. Emsley R, Kilian S. Efficacy and safety profile of paliperidone palmitate injections in the management of patients with schizophrenia: an evidence-based review. Neuropsychiatr Dis Treat 2018;14:205-223.

33. Ongür D, Lin L, Cohen BM. Clinical characteristics influencing age at onset in psychotic disorders. Compr Psychiatry 2009;50:13-19.

34. Bertani M, Lasalvia A, Bonetto C, Tosato S, Cristofalo D, Bissoli S, et al. The influence of gender on clinical and social characteristics of patients at psychosis onset: a report from the Psychosis Incident Cohort Outcome Study (PICOS). Psychol Med 2012;42:769-780.

35. O’Donoghue B, Lyne J, Madigan K, Lane A, Turner N, O'Callaghan E, et al. Environmental factors and the age at onset in first episode psychosis. Schizophr Res 2015;168:106-112.

36. Ochoa S, Usall J, Cobo J, Labad X, Kulkarni J. Gender differences in schizophrenia and first-episode psychosis: a comprehensive literature review. Schizophr Res Treatment 2012; 2012:916198.

37. Regier DA, Farmer ME, Rae DS, Locke BZ, Keith SJ, Judd LL, et al. Comorbidity of mental disorders with alcohol and other drug abuse. Results from the Epidemiologic Catchment Area (ECA) study. JAMA 1990;264:2511-2518.

38. de Leon J, Diaz FJ. A meta-analysis of worldwide studies demonstrates an association between schizophrenia and tobacco smoking behaviors. Schizophr Res 2005;76:135-157.

39. Anthony JC, Lopez-Quintero C, Alshaarawy O. Cannabis epidemiology: a selective review. Curr Pharm Des 2017;22: 6340-6352.

40. Arseneault L, Cannon M, Poulton R, Murray R, Caspi A, Moffitt TE. Cannabis use in adolescence and risk for adult psychosis: longitudinal prospective study. BMJ 2002;325:1212-1213.

41. Marconi A, Di Forti M, Lewis CM, Murray RM, Vassos E. Meta-analysis of the association between the level of cannabis use and risk of psychosis. Schizophr Bull 2016;42:12621269. 